\title{
ESTUDO DA DISSECAÇÃO DO RELEVO NO ALTO RIO PIRANGA (MG)
}

\author{
RELIEF DISSECTION STUDY IN THE HIGH PIRANGA RIVER (MG) \\ William Zanete BERTOLINI ${ }^{1}$, Sandra Cristina DEODORO ${ }^{2}$ \\ ${ }^{1}$ Universidade Federal da Fronteira Sul, Câmpus Chapecó, SC. Email: geozaneti@hotmail.com \\ ${ }^{2}$ Universidade Federal de Minas Gerais.Email: sdeodoro@hotmail.com \\ Introdução \\ Procedimentos técnicos e metodológicos \\ Classificação das Rochas Carbonatíticas \\ Caracterização da área de estudo \\ Resultados \\ Considerações Finais \\ Agradecimentos \\ Referências
}

\begin{abstract}
RESUMO - A avaliação do grau de dissecação permite a avaliação morfodinâmica da paisagem e o reconhecimento de padrões diferenciados de rugosidade da superfície. Com o objetivo de avaliar a dissecação no alto rio Piranga (MG) este trabalho analisa de duas maneiras diferentes essa variável, discutindo-a junto ao quadro morfogenético dessa área de estudo. Os dois modos de avaliação da dissecação foram: por meio da mensuração de distâncias interfluviais e entalhamento médio de vales sobre carta topográfica e sua espacialização pela ferramenta Kernel e a outra obtida indiretamente por meio da espacialização do Índice de Concentração de Rugosidade (ICR). A comparação entre os dois modos de avaliação permitiu afirmar que eles não são equivalentes. Para o alto rio Piranga, a espacialização da dissecação com base na utilização da ferramenta Kernel a partir do entalhamento médio X distância interfluvial dos vales mostrou-se mais condizente com a realidade do que a espacialização via ICR. Do ponto de vista morfogenético, a dissecação do relevo do alto rio Piranga permite invalidar a suposição de um processo de rejuvenescimento da paisagem mais avançado no planalto inferior do que no planalto superior.
\end{abstract}

Palavras-chave: Entalhamento, Relevo, ICR, Rio Piranga.

\begin{abstract}
The evaluation of the degree of dissection allows the morphodynamic evaluation of the landscape and the recognition of differentiated patterns of surface roughness. In order to evaluate dissection in the upper Piranga River (MG), this work evaluates this variable in two different ways, discussing it together with the morphogenetic picture of this area of study. The two modes of evaluation of the dissection were: through the measurement of interfluvial distances and average grooving of valleys on topographic chart and its spatialisation by the Kernel tool and the other obtained indirectly by means of the spatialization of the Roughness Concentration Index (ICR). The comparison between the two modes of evaluation allowed asserting that they are not equivalent. For the upper Piranga River, the spatialization of the dissection based on the use of the Kernel tool from the middle notch X interfluvial distance of the valleys proved to be more consistent with the reality than the spatialization via ICR. From the morphogenetic point of view, the dissection of the relief of the upper Piranga River makes it possible to invalidate the assumption of a process of rejuvenation of the more advanced landscape in the lower plateau than in the upper plateau.
\end{abstract}

Keywords: Carving, Relief, ICR, Piranga River.

\section{INTRODUÇÃO}

A dissecação é uma característica do relevo que reflete a energia que perpassa determinado sistema geomorfológico ao longo de sua esculturação recente. Por isso a mensuração desta variável constitui instrumento importante para avaliação morfodinâmica da paisagem. Relevos muito dissecados são constituídos de vales profundos ou incisos e topos pouco largos. Além de permitir o estabelecimento de um padrão de compartimentação geomorfológica, o grau de dissecação permite também inferir intensidades diferenciadas nos processos desnudacionais recentes responsáveis pela esculturação da superfície. Quando se identificam áreas com dissecações muito diferenciadas, é possível supor que tenha havido tempos distintos de atuação de agentes morfodinâmicos como rios e escoamento superficial na configuração da paisagem. Esta ideia embasa a hipótese considerada neste trabalho, de que, pela análise da dissecação geomorfológica, procurou-se saber se havia um padrão de dissecação diferenciado entre os dois compartimentos planálticos da área estudada e, consequentemente, se com isso poderia se afirmar a respeito de tempos distintos de morfogênese, associado a um processo de rejuvenescimento do relevo do planalto inferior em relação ao compartimento do planalto superior.

A intensidade de dissecação ou, como também se costuma chamar, a intensidade de rugosidade topográfica é o primeiro grande indicador da fragilidade potencial que $\mathrm{o}$ ambiente natural apresenta. A densidade de drenagem associada ao grau de entalhamento dos canais combinados determina a rugosidade topográfica ou o índice de dissecação do relevo, e obviamente, define a dimensão interfluvial média dos conjuntos homogêneos de formas ou conjuntos de formas semelhantes (ROSS, 2003, p.73). 
No trabalho pioneiro de mapeamento geomorfológico do território brasileiro, realizado pelo projeto RADAM nas décadas de 1970 e 1980, a consideração da dissecação do relevo começou a ser empregada como meio de simplificar a representação de colinas, cristas e interflúvios tabulares, formas às quais foram associados dois dígitos de 1 a 5 de modo a distinguir a extensão delas e o aprofundamento da drenagem. Essa tarefa foi de fundamental importância para a distinção de padrões nas imagens de radar utilizadas (BARBOSA et al., 1984).

Com o avanço e desenvolvimento dos Sistemas de Informação Geográfica (SIG) em meio computadorizado (geoprocessamento), a dissecação do relevo tem sido inferida, indiretamente, a partir do Índice de Concentração de Rugosidade (ICR) proposto por Sampaio (2008) nos estudos da rede de drenagem da bacia do rio Benevente (ES). Esse índice foi obtido através de uma matriz de declividade transformada em um conjunto de pontos sobre os quais se aplicou o estimador de densidade de Kernel - uma ferramenta geoestatística para análise espacial de densidade de valores ou de comportamento de padrões.

Com o objetivo de avaliar a dissecação do relevo no alto rio Piranga este trabalho traz resultados obtidos por Bertolini (2015), discutindo-os junto ao quadro morfogenético dessa área de estudo, por meio de duas metodologias de avaliação da dissecação do relevo: uma obtida a partir da mensuração de distâncias interfluviais e entalhamento médio de vales sobre carta topográfica e associados à sua espacialização e outra obtida indiretamente por meio da espacialização do Índice de Concentração de Rugosidade (ICR).

\section{PROCEDIMENTOS TÉCNICOS E METODOLÓGICOS}

Existem variadas fórmulas de mensuração da dissecação do relevo. Aqui foram consideradas duas formas para a obtenção da dissecação do relevo do alto rio Piranga em Minas Gerais. A primeira, derivada diretamente da mensuração da distância interfluvial e desnível altimétrico entre topo e fundo de vale (entalhamento médio) sobre as cartas topográficas Capela Nova (IBGE, 1976) e Senhora dos Remédios (IBGE, 1976), ambas em escala 1:50.000. Nesse caso, foram aproveitados os pontos cotados existentes para cotação das altitudes máximas enquanto as altitudes mínimas (fundo de vale) foram estimadas a partir das curvas de nível. A segunda maneira de avaliar a dissecação foi derivada indiretamente, a partir do Índice de Concentração de Rugosidades (ICR), considerando os valores de declividade gerados a partir de curvas de nível do modelo
SRTM (equidistância de 30m).

A primeira maneira de avaliar a dissecação do relevo foi empregada pelo Projeto RADAM BRASIL e por ROSS (1992; 2003) considerando a dimensão interfluvial e o entalhamento médio dos vales. Dessa maneira, cinco classes de dissecação, conforme o cruzamento dessas duas variáveis (dimensão interfluvial e entalhamento médio dos vales) são propostas. O entalhamento médio é dado em função da mensuração a partir das duas vertentes de uma seção de vale (indicado por transectos aleatórios), partindo-se do fundo de vale até o seu topo. Neste caso, a classificação da dissecação em muito fraca, fraca, média, forte ou muito forte foi realizada levando-se em conta a adaptação da matriz de dissecação de Ross (2003) por Messias \& Trovó (2013) para a escala de 1:50.000 (Figura 1).

\begin{tabular}{|c|c|c|c|c|c|}
\hline \multirow[b]{2}{*}{$\begin{array}{l}\text { Entalhamento } \\
\text { médio }(\mathrm{m})\end{array}$} & \multicolumn{5}{|c|}{ Distância interfluvial (m) } \\
\hline & $\begin{array}{l}\text { Muito grande } \\
\quad>3750\end{array}$ & $\begin{array}{c}\text { Grande } \\
1750 \text { a } 3750\end{array}$ & $\begin{array}{c}\text { Média } \\
750 \text { a } 1750\end{array}$ & $\begin{array}{l}\text { Pequena } \\
250 \text { a } 750\end{array}$ & $\begin{array}{c}\text { Muito } \\
\text { pequena } \\
<250\end{array}$ \\
\hline \multicolumn{6}{|l|}{ Muito fraco $<20$} \\
\hline \multicolumn{6}{|l|}{ Fraco 20 a 40} \\
\hline \multicolumn{6}{|l|}{ Médio 40 a 80} \\
\hline \multicolumn{6}{|l|}{ Forte 80 a 160} \\
\hline \multicolumn{6}{|l|}{ Muito forte $>160$} \\
\hline \multicolumn{6}{|c|}{ Dissecação } \\
\hline & Muito fraca & Fraca & Média & Forte & Muito forte \\
\hline
\end{tabular}

Figura 1 - Matriz de dissecação do relevo levando-se em conta o entalhamento médio X distância interfluvial. Fonte: Messias \& Trovó (2013). 
Foram traçados 302 transectos sobre as cartas topográficas para a mensuração da distância interfluvial e do desnível altimétrico entre topo e fundo de vale (entalhamento médio), de modo a se realizar uma amostragem significativa da dissecação da área de estudo. A partir dos resultados obtidos por meio dessa mensuração amostral (transectos), elaborou-se o mapa de dissecação do relevo com base no estimador de densidade de Kernel. Esta ferramenta foi utilizada para se obter a espacialização areal e contínua em toda a área de estudo já que os transectos amostrados de maneira manual representam uma amostragem pontual e descontínua.

A avaliação da dissecação por meio do ICR foi adotada conforme Souza (2008) e Souza \& Sampaio (2010). Sampaio (2008) propôs o ICR nos estudos da rede de drenagem da bacia do rio Benevente (ES) quando de sua pesquisa de doutorado. Trata-se de um índice obtido em ambiente SIG, pela aplicação do estimador de densidade de Kernel sobre valores de declividade (ou sobre shapefile de pontos de valores de declividade). É utilizado, também, para identificação de feições geomorfológicas.

Este índice estima a rugosidade do relevo através da análise do comportamento espacial (concentração ou densidade) dos valores da declividade. Na linguagem do geoprocessamento, o ICR é obtido através da conversão da matriz de declividade (formato raster) em uma malha de pontos (formato shapefile), analisada, posteriormente, pelo estimador de densidade de Kernel. Este é um método geoestatístico utilizado em análise espacial para verificar a dispersão ou concentração de um fenômeno espacial (no caso, dos valores de declividade para o ICR) por meio de um raio de abrangência.

O papel do Kernel é interpolar um valor de intensidade para cada amostra em uma área, considerando uma função simétrica, centrada nas amostras, utilizando para o cálculo os pontos situados até certa distância do centro da amostra (Oliveira et al., 2011 segundo Messias \& Trovó, 2013).

O ICR é baseado no Índice de Rugosidade de Hobson (1972) o qual consiste em um grid de células com um valor único de rugosidade para cada uma delas. Sampaio (2008), com base em Hobson (1972) e através do estimador de densidade de Kernel, analisou a concentração espacial da rugosidade e identificou unidades morfológicas distintas, eliminando a classificação pontual do relevo (Nascimento et al., 2010).

Ferrari et al. (1998), em análise morfométrica da superfície cárstica do Núcleo Cablocos, no Vale do Ribeira, com a utilização do Índice de Rugosidade (Hobson, 1972), indicam que sem a aplicação daquele estimador de densidade, pode haver mesmo Índice de Rugosidade para terrenos com características diferentes, o que não ocorre no ICR (Nascimento et al., 2010).

Conforme proposto por Sampaio (2008) em seus estudos, o ICR pode ser local (raio de 565 $\mathrm{m}$, equivalente a $1 \mathrm{~km} 2$ ) ou global. No primeiro caso, é utilizado para identificação exploratória de unidades locais de relevo, através de raio de busca livre; no segundo caso, o ICR é empregado para análise regional e comparativa entre unidades de relevo, utilizando-se um raio de busca de $1.128 \mathrm{~m}$ - equivalente a aproximadamente 4 km2 (Sampaio \& Augustin, 2014a).

Além desses autores, o ICR vem sendo adotado em estudos geomorfológicos que envolvem análises de dissecação do relevo, como por exemplo, em Sampaio \& Augustin (2014b), Messias \& Trovó (2013), Souza \& Sampaio (2010) e Fonseca (2010), dentre outros.

Apesar de ser uma técnica de obtenção indireta da dissecação por meio da declividade, o ICR possui a vantagem de otimizar a espacialização da variável através de Sistema de Informação Geográfica.

Neste artigo, para o estudo da dissecação do relevo do alto rio Piranga, adotou-se o ICR global. Após vários testes de raios de busca e com base na relação entre raio e área (Sampaio, 2010; Sampaio \& Augustin, 2014a), adotou-se um valor de raio de 1000 metros para análise da concentração espacial da rugosidade, que representou melhor a realidade geomorfológica da área de estudo. Além disso, foram testados vários métodos de distribuição dos valores por classes (quantil, quebras naturais, intervalos iguais, intervalos geométricos, desvio padrão) para melhor representar visualmente os resultados. Dentre eles, a distribuição por quebras naturais apresentou-se mais coerente com a realidade da paisagem da área de estudo. 


\section{CARACTERIZAÇÃO DA ÁREA DE ESTUDO}

A alta bacia do rio Piranga localiza-se na região centro-sul de Minas Gerais (Figura 2) e limita-se, a oeste, com a bacia do rio Carandaí, afluente do rio Grande (bacia do Paraná). Em termos tectono-estruturais, o alto rio Piranga localiza-se entre a porção sul do Cráton São Francisco e a Província Mantiqueira e faz parte dos chamados Complexos Granito-Gnáissicos, uma das unidades geotectônicas básicas dos Cinturões Paleoproterozoicos no Estado de Minas Gerais. O Mapa Geológico do Estado de Minas Gerais (1:1.000.000) (COMIG et al., 2003), bem como Delgado et al., (2003), permitem situar a área de estudo como parte integrante do Cinturão Mineiro (Paleoproterozoico), na porção sul da Província São Francisco.

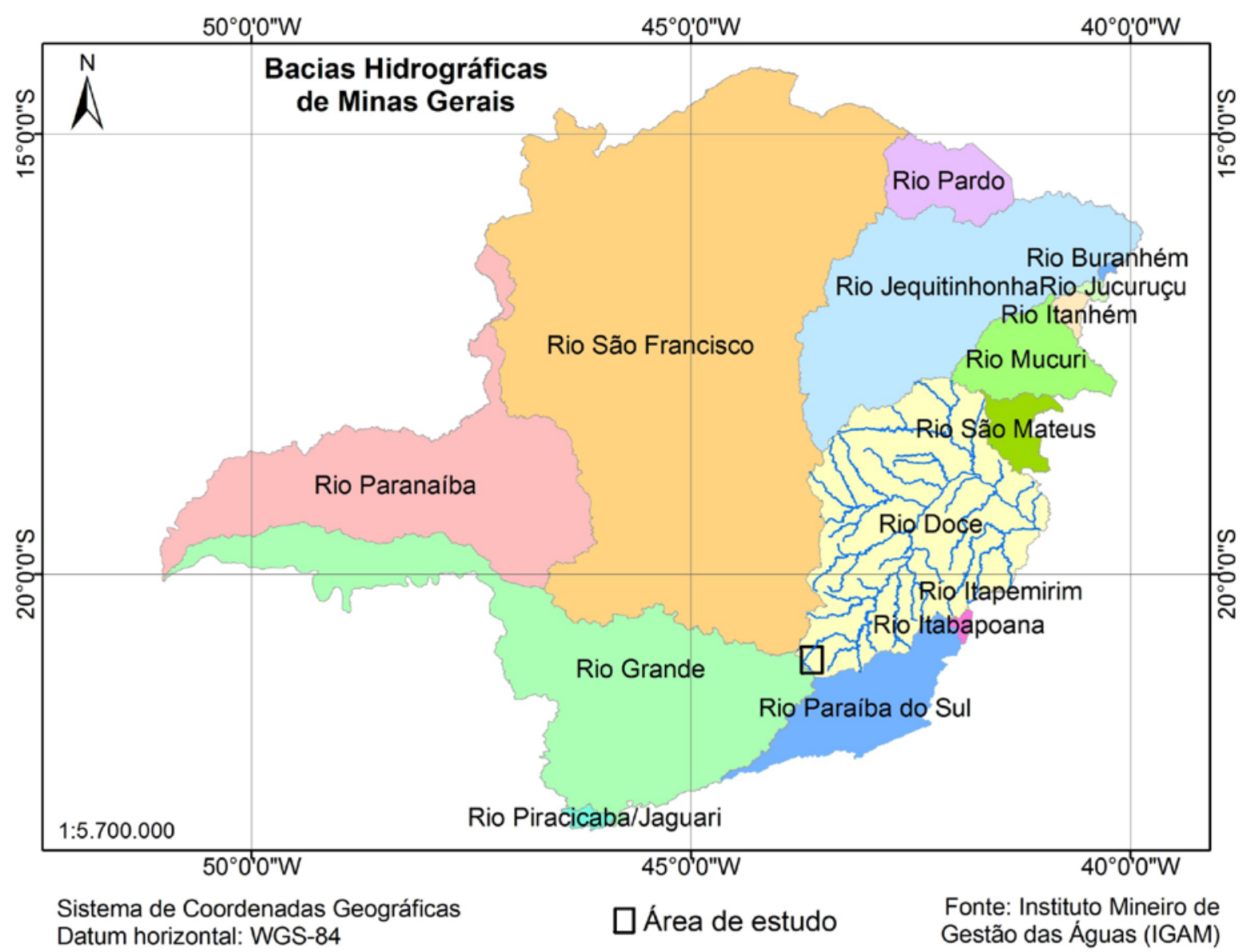

Figura 2 - Localização da área de estudo (alto rio Piranga) na bacia do rio Doce - Estado de Minas Gerais.

Do ponto de vista geomorfológico, a região centro-sul de Minas faz parte do Planalto dos Campos das Vertentes (RADAM BRASIL, 1983), Planalto Centro-Sul Mineiro (CETEC, 1982) ou Planalto Atlântico (Ab’Saber, 1950). Trata-se de uma área contida no domínio dos escudos expostos do sudeste brasileiro. Em termos regionais, o alto rio Piranga é caracterizado por um modelado de desnudação em interflúvios e vertentes com dissecação variando de fraca a profunda; com um relevo de morros e colinas com vertentes convexas e côncavas e topos convexizados (RADAM BRASIL, 1983).

Dois compartimentos planálticos fazem parte da área de estudo: um mais elevado, aqui denominado de planalto superior, com altitudes de cerca de 1000 a 1300 metros e outro rebaixado, denominado de planalto inferior, com altitudes que variam em torno de 680 a 890 metros. A hipsometria da área de estudo ilustra bem tal compartimentação geomorfológica marcada por dois compartimentos planálticos separados por uma escarpa (Figura 3). A declividade predominante na região está entre 5 a 20 graus (ou 9\% a 36\%, aproximadamente) com destaque para declives maiores que 20 graus nas cabeceiras dos vales em ambos compartimentos planálticos e na escarpa (Figura 3). Essa escarpa, reconhecida por Cherem et al., (2013), como de caráter erosivo é denominada em alguns de seus 
trechos pelas toponímias de Serra do Bom Jardim, Serra do Manhoso, Serra do Ferra Burro. Cherem et al. (2013) caracterizaram tal escarpa, também denominada como Degrau de Barbacena, com uma extensão de 60,2 km e sentido principal N30W. Afirmam tratar-se de uma escarpa erosiva onde não há um controle litoestrutural determinante, resultante da diferença do potencial erosivo entre as

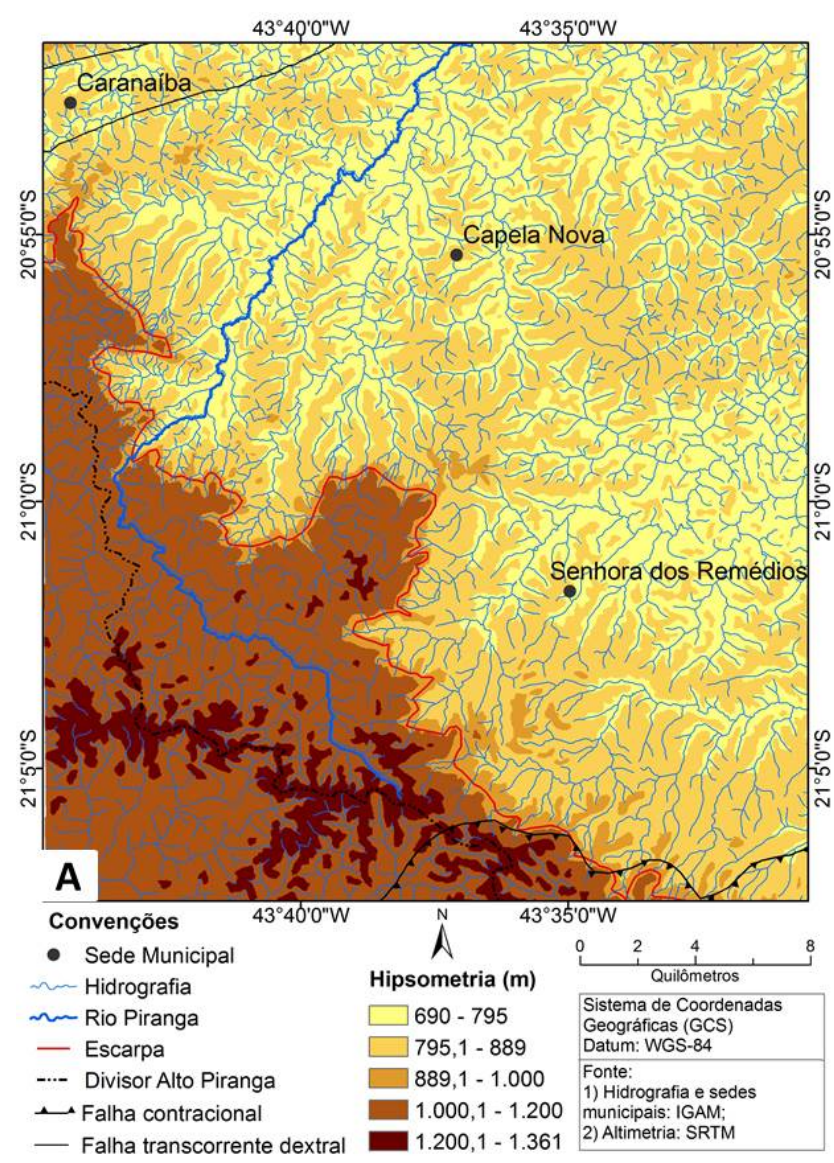

cabeceiras de drenagem do planalto inferior e superior (Cherem et al, 2013, p.300). Tal compartimentação é resultante de uma história geomorfológica marcada pela retração do escarpamento que separa o alto e o baixo planalto e pela captura do alto rio Piranga por meio da atividade erosiva remontante de um paleocurso pertencente à bacia do rio Doce (Cherem et al., 2013; Bertolini, 2015).

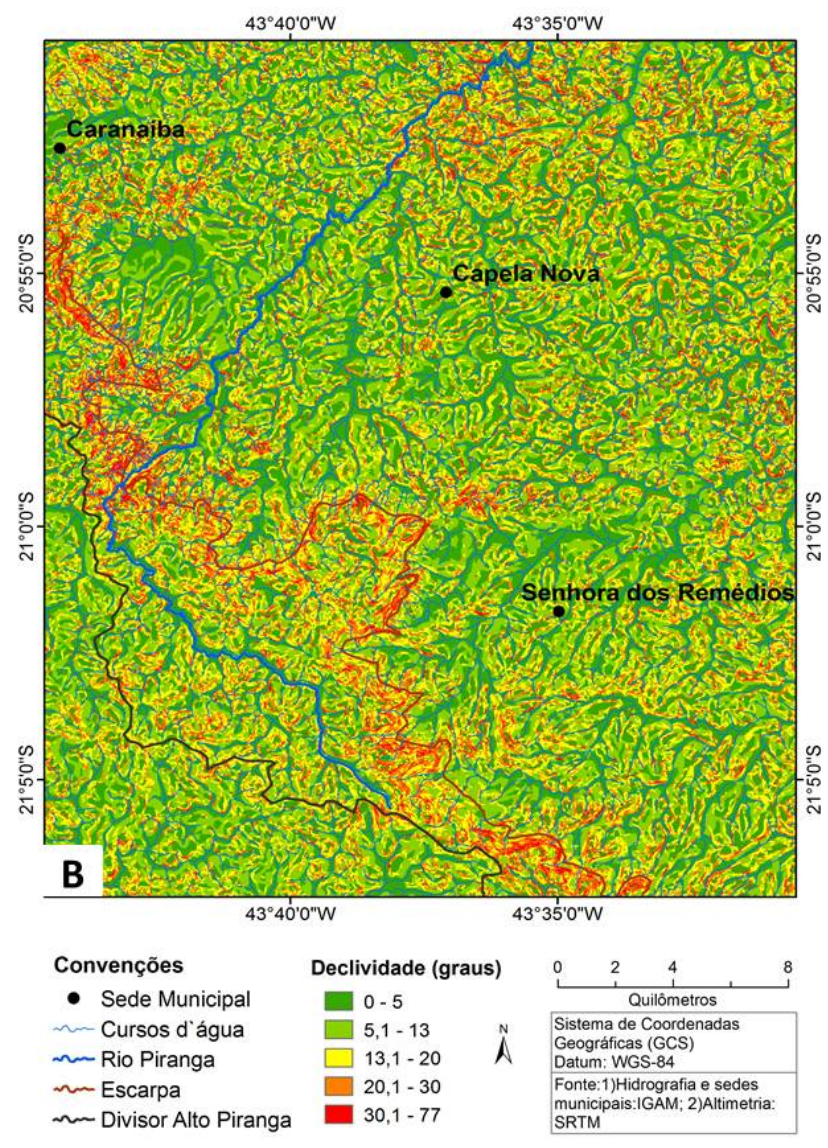

Figura 3 - Bacia do Alto Rio Piranga: A) Mapa de Hipsometria. B) Mapa de declividade.

\section{RESULTADOS}

A avaliação da dissecação do relevo em termos da dimensão interfluvial e do entalhamento médio, mensurados manualmente sobre carta topográfica, permite dizer que tanto no planalto superior quanto no inferior o grau de dissecação é predominantemente forte, variando a média e em menor medida a muito forte (Figura 4). Dos 302 transectos realizados, 105 foram classificados como de dissecação média, 187 como de dissecação forte e 10 com dissecação muito forte (Figura 4). Dessa maneira, pode-se afirmar que ambos os compartimentos planálticos apresentam um entalhamento médio dos vales de 80 a 160 metros e distância interfluvial de 250 a 750 m.
Nota-se também um imbricamento de transectos representativos de dissecação média e forte, que parece indicar uma variação local da dissecação de vale para vale, provavelmente conforme caraterísticas locais dos cursos d’água.

A espacialização dos transectos da Figura 4, por meio da aplicação da ferramenta Kernel, deu como resultado o mapa da dissecação do relevo conforme a Figura 5. Entende-se que a ferramenta Kernel mostrou-se útil à representação da dissecação obtida manualmente (Figura 4) com a vantagem de tornar as variáveis pontuais (transectos) em variáveis areais espacializadas de modo contínuo e fiel à realidade. 


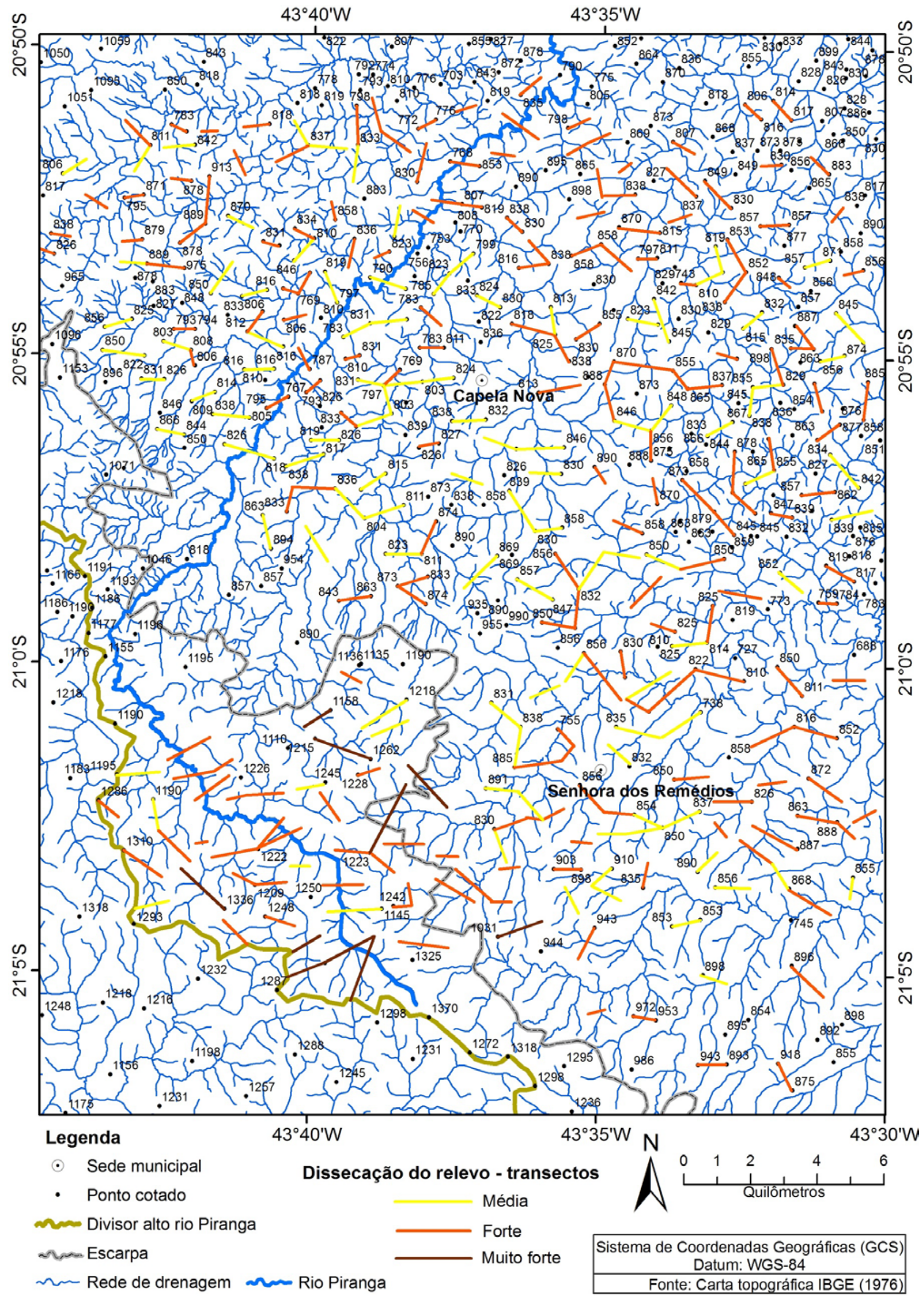

Figura 4 - Dissecação pontual do relevo a partir do entalhamento médio X dimensão interfluvial sobre carta topográfica. 


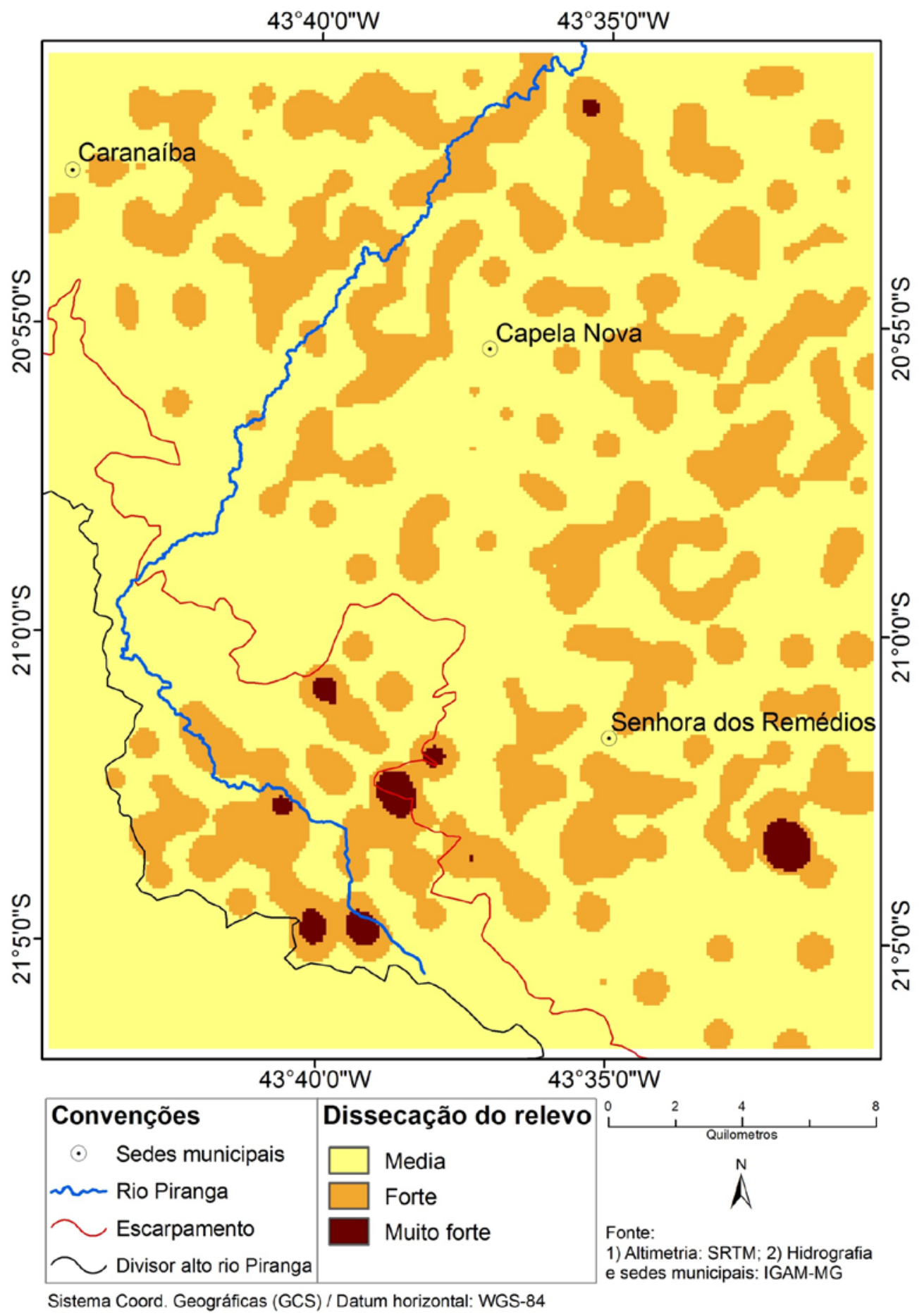

Figura 5 - Dissecação areal do relevo a partir do entalhamento médio X distância interfluvial com a ferramenta Kernel.

Já a partir da espacialização do Índice de Concentração de Rugosidade - ICR - a mesma análise pode ser feita, com a ressalva de que é necessário cuidado na escolha do método a ser adotado na definição de classes e do raio de busca para evitar inconsistências no mapeamento do ICR, sobretudo em termos de amplitudes espaciais menores. A escolha dessas duas variáveis interfere diretamente na espacialização dos valores e na maior ou menor amplitude das classes desses valores. O método estatístico adotado na distribuição espacial das classes do ICR foi o de quebras naturais e o raio de busca de 1000 m para o estimador Kernel. Esse raio mostrou-se o mais condizente com a dissecação avaliada manualmente sobre a carta topográfica. A Figura 6 apresenta o resultado do ICR e sua correspondência com o mapa de relevo sombreado, onde se pode observar rugosidades mais expressivas (valores mais altos de concentração) na área da escarpa que separa o planalto superior do inferior. 

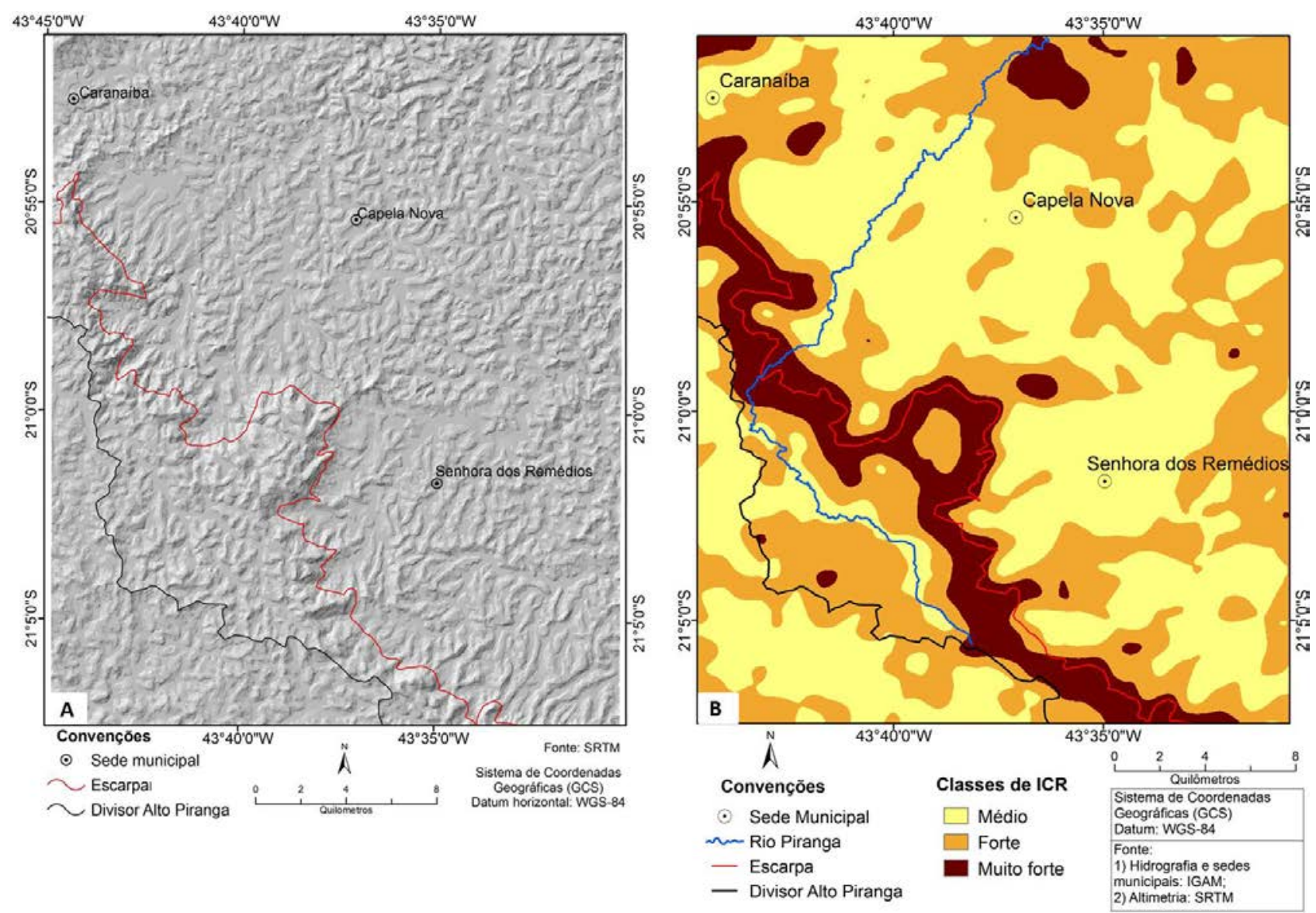

Figura 6 - A) Relevo sombreado. B) Mapa de Índice de Concentração de Rugosidade - ICR.

O mapa da dissecação, obtido por meio da mensuração do entalhamento médio e da distância interfluvial do relevo, e o mapa do ICR apresentaram resultado em 3 classes, caracterizando a paisagem local. Assim como no método direto do cálculo da dissecação do relevo, no ICR os maiores valores predominaram na área da escarpa (Figura 6), com nítido destaque a ela demonstrado também no mapa do relevo sombreado e no da declividade.

A comparação da espacialização dos dois modos de avaliar a dissecação apresentou diferenças de classificação para áreas iguais, como por exemplo, no entorno da sede urbana de Senhora dos Remédios. Também houve uma superestimação de pequenas áreas no planalto inferior com rugosidade muito forte, não associadas a entalhamentos/incisões e distâncias interfluviais pronunciadas. Ressaltase também que a diferenciação junto da escarpa foi significativa. No entanto, isto foi devido à pequena amostragem de transectos realizada sobre esta feição geomorfológica, tendo em vista que tanto os declives quanto a incisão das cabeceiras de vales aí localizadas são muito pronunciadas, com desníveis verticais de mais de 80 metros. Ao analisar o resultado da dissecação nesta área pelo método direto mostrado na Figura 5, este se mostrou mais condizente à realidade (também constatada em campo) do que o resultado do ICR. Importante ressaltar, entretanto, que um método leva em conta a declividade e o outro não. Por outro lado, ambos os resultados mostraram-se semelhantes em áreas do planalto inferior, como nas proximidades de Caranaíba e Capela Nova. Outras áreas onde os resultados também foram semelhantes são aquelas entre o divisor do alto rio Piranga e o seu vale onde predominaram a forte dissecação e a forte concentração da rugosidade do relevo. A comparação entre os dois modos de espacializar a dissecação do relevo permite dizer que estes dois modos não são equivalentes mas sim complementares. Para o alto rio Piranga, a espacialização da dissecação com base na utilização da ferramenta Kernel a partir de transectos baseados na relação entalhamento médio X distância interfluvial mostrou-se mais condizente com a realidade do que a espacialização via ICR. 
Em termos morfogenéticos, a avaliação da dissecação permite invalidar a suposição de um processo de rejuvenescimento da paisagem mais avançado no planalto inferior do que no planalto superior. Isto porque as incisões da drenagem não são menos profundas lá em relação ao planalto superior. E em termos energéticos, há uma clara transferência de energia entre esses dois compa- timentos planálticos, o que reforça a ideia de que a paisagem regional está em processo ativo de desmonte desnudacional corroborando a ideia de Cherem et al., (2013) de que a escarpa é, na verdade, uma feição do relevo que marca a diferença de potencial energético entre duas áreas distintas e não está associada a controle litoestrutural ativo.

\section{CONSIDERAÇÕES FINAIS}

A análise das duas diferentes maneiras de mensurar e espacializar a dissecação do relevo permitiu observar que a dissecação a partir do entalhamento médio dos vales $\mathrm{X}$ dimensão interfluvial com a ajuda da ferramenta Kernel apresentou-se mais coerente para analisar a dinâmica da paisagem local do alto rio Piranga do que a espacialização da rugosidade pelo ICR global - que se ajustou melhor à área de estudo do que o ICR local pelos raios de busca. Por outro lado, apesar de apresentar relação direta com apenas uma característica de relevo, ou seja, a declividade, o ICR procura um padrão de comportamento para a rugosidade em um dado recorte espacial, apresentando-se útil para uma caracterização da paisagem do ponto de vista de seu potencial energético.

Há de se considerar a natureza metodológica de ambas as técnicas: uma é realizada em ambiente bidimensional através de perfis topográficos, em uma análise pontual, absoluta; a outra se realiza em ambiente tridimensional (declividade obtida por um modelo de elevação), sob análise zonal, espacialmente abrangente. Desta forma, a escolha e aplicação de uma ou outra metodologia dependerão do objetivo e da escala de trabalho.

\section{AGRADECIMENTOS}

Os autores agradecem ao Conselho Nacional de Desenvolvimento Tecnológico (CNPQ) a concessão de bolsa de doutorado ao primeiro autor e à Bios Consultoria.

\section{REFERÊNCIAS}

AB'SABER, A.N. Sucessão de quadros paleogeográficos no Brasil do Triássico ao Quaternário. Anuário da Faculdade de Filosofia - Sedes Sapientiae 1950-1951; Universidade Católica de São Paulo, p.61-69. 1950.

BARBOSA, G.V.; SILVA, T.C.; NATALI FILHO, T.; DEL' ARCO, D.M.; COSTA, R.C.R. Evolução da metodologia para mapeamento geomorfológico do projeto Radam Brasil. Boletim Técnico Projeto Radam Brasil. Série Geomorfologia, n. 1, p. 187. 1984.

BERTOLINI, W.Z. A alta bacia do rio Piranga (MG): estudo geomorfológico a propósito da condição de equilíbrio do relevo. 2015. 207p. Tese (Doutorado em Ciências), Faculdade de Filosofia, Letras e Ciências Humanas. Universidade de São Paulo.

CHEREM, L.F.S.; VARAJÃO, C.A.C.; MAGALHÃES JUNIOR, A.P.; SALGADO, A.A.; OLIVEIRA, L.A.F.; BERTOLINI, W.Z.; VARAJÃO, A.F.D.C. O papel das capturas fluviais na morfodinâmica das bordas interplanálticas do sudeste do Brasil. Revista Brasileira de Geomorfologia, v. 14, n. 4. p. 299-308. 2013.

CETEC - FUNDAÇÃO CENTRO TECNOLÓGICO DE MINAS GERAIS. Mapa Geomorfológico do Estado de Minas Gerais. Belo Horizonte. Escala da base cartográfica: 1:1.000. 000. 1982.

COMIG - Companhia Mineradora de Minas Gerais; CPRM Serviço Geológico do Brasil. Mapa Geológico do Estado de Minas Gerais. Escala 1:1.000.000, Belo Horizonte, MG. 2003.

DELGADO, I.M.; SOUZA, J.D; SILVA, J.C.; FILHO, N.C.S.; SANTOS, R.A.; PEDREIRA, A.J.; GUIMARÃES, J.T.;
ANGELIM, J.A.A.; VASCONCELOS, A.M.; GOMES, I.P.; FILHO, J.V.L.; VALENTE, C.R.; PERROTTA, M.M; HEINECK, C.A. Geotectônica do Escudo Atlântico (cap. V). In: BIZZI, L.A.; SCHOBBENHAUS, C.; VIDOTTI, R.M.; GONÇALVEZ, J.H (eds). Geologia, Tectônica e Recursos Minerais do Brasil. CPRM, Brasília. 2003.

FERRARI, J.A.; HIMURA, S.T.; KARMANN, I. Caracterização Morfométrica de uma Superfície Cárstica do Vale do Ribeira, São Paulo (Núcleo Caboclos - PETAR). Revista do Instituto Geológico, v.19, p. 9-17, 1998.

FONSECA, B.M. O uso dos Sistemas de Informações Geográficas na Análise Morfométrica e Morfológica de Bacias de Drenagem na Serra do Espinhaço MeridionalMG. 2010. Dissertação (Mestrado em Geografia e Análise Ambiental), Universidade Federal de Minas Gerais. Belo Horizonte.

HOBSON, R.D. Surface roughness in topography: quantitative approach. In: Chorley (ed.) Spatial analysis in geomorphology. Harper and Row. New York, NY, p. 225245. 1972.

IBGE - INSTITUTO BRASILEIRO DE GEOGRAFIA E ESTATÍSTICA. Carta topográfica Capela Nova Folha SF23-X-A-VI-4. Escala 1:50.000. 1976.

IBGE - INSTITUTO BRASILEIRO DE GEOGRAFIA E ESTATÍSTICA. Carta topográfica Senhora dos Remédios Folha SF-23-X-C-III-2. Escala 1:50.000. 1976.

MESSIAS, C.G. \& TROVÓ, D.F.G. Dissecação do relevo da área de influência da hidrelétrica do Funil (MG): uma comparação entre os métodos de mapeamento manual e Índice de Concentração de Rugosidades. In: SIMPÓSIO 
NACIONAL DE GEOMORFOLOGIA, 9, 2013. Rio de Janeiro Anais... Rio de Janeiro:

NASCIMENTO, E.R.; NETO, J.M.R.; REBELO, A.M.A. Aplicação do Índice de Concentração da Rugosidade do relevo no entendimento do nível de exposição dos sistemas cársticos ocorrentes na região norte do município de Curitiba, PR. Revista Brasileira de Geomorfologia, v. 11, n 2, 2010.

RADAM BRASIL. Mapa geomorfológico. Folha Rio de Janeiro/Vitória SF23/24. Escala 1:1.000.000. Levantamento de Recursos Naturais. v. 32. Ministério das Minas e Energia. 1983.

ROSS, J.L.S. Geomorfologia Ambiente e Planejamento. Ed. Contexto. São Paulo. 85p. 2003.

SAMPAIO, T.V.M. Parâmetros morfomé-tricos para melhoria da acurácia do mapeamento da rede de drenagem - uma proposta baseada na análise da Bacia Hidrográfica do Rio Benevente - ES. 2008. Tese (Doutorado em Geografia), Universidade Federal de Minas Gerais. Belo Horizonte.

SAMPAIO, T.V.M.; AUGUSTIN, T.H.R.R. Variáveis auxiliares para o mapeamento da rede de drenagem: correlação espacial entre nascentes, unidades de relevo e litotipos na bacia hidrográfica do rio Benevente-ES. GEOUSP - Espaço e Tempo, São Paulo, v. 18, n. 3, p. 624-634, 2014(a).

SAMPAIO, T.V.M. \& AUGUSTIN, C.H.R.R. Índice de Concentração da Rugosidade: uma nova proposta metodológica para o mapeamento e quantificação da dissecação do relevo como subsídio a cartografia geomorfológica. Revista Brasileira de Geomorfo-logia, v. 15, n.1, 2014(b).

SOUZA, L.F. \& SAMPAIO, T.V.M. Aplicação do Índice de Concentração de Rugosidade à identificação de classes de dissecação do relevo: uma proposta de quantificação e automatização em ambiente SIG. In: SIMPÓSIO BRASI-LEIRO DE CIÊNCIAS GEODÉSICAS E TECNOLOGIAS DA GEOINFORMAÇÃO, III, 2010, Recife. Anais ...Recife.

Submetido em 7 de abril de 2017 Aceito em 19 de outubro de 2017 